\title{
Poetas viéndose pensar: supuestos de frontalidad metacognitiva en poesía española contemporánea*
}

\section{Poets Watching Themselves in the Process of Thinking: Cases of Metacognitive Frontality in Peninsular Contemporary Poetry}

\author{
Vicente-Luis Mora \\ Universidad Internacional de la Rioja \\ vicenteluis.mora@unir.net \\ ORCID iD: https://orcid.org/0000-0002-2718-4685
}

\section{RESUMEN}

Algunos poetas españoles contemporáneos están reelaborando la tradición romántica de describir el estado de conciencia y los procesos mentales de construcción de sentido en poemas meditativos. Estos textos se vertebran como mecanismos líricos en virtud de los cuales los poetas se describen pensándose o mirándose a sí mismos mirando o pensando. El cerebro en estas obras semeja un paisaje espacial o una escena en la que la representación se figura como un acto de lenguaje encarnado o una pregunta por los límites del discurso poético para expresar pensamientos. En una significativa señal de autoconciencia, algunos de estos poetas usan incluso términos o conceptos tomados de la neurociencia. Estos procedimientos pueden ser vistos como casos de metacognitividad, ligada al resultado de una gran actividad neuronal ubicada en el córtex prefrontal. Este artículo explora una lectura cognitiva de estos poemas desde una perspectiva neurocientífica para discernir nuevas dimensiones de la metapoética autoexploradora o de la meta-autoexploración poética.

Palabras Clave: poesía; conciencia; autoexploración; cognición.

\begin{abstract}
Some of the contemporary Spanish poets are re-elaborating the romantic tradition of describing the neural state of consciousness and processes of meaning-making in meditative poems.

\footnotetext{
* Este artículo se enmarca en el Proyecto de Investigación con título Inscripciones literarias de la ciencia: cognición, epistemología y epistemocrítica (ILICIA), subvencionado por el Ministerio de Economía y Competitividad (Proyectos de I+D, del Programa Estatal de Fomento de la Investigación Científica y Técnica de Excelencia, Subprograma Estatal de Generación de Conocimiento). Ejecución: 2018/2020 (ambos inclusive). Ref. FFI2017-83932-P.
} 
These texts are constructed as lyric mechanisms whereby the poets describe themselves seeing or thinking in themselves thinking or seeing. The brain in these oeuvres appears to be a spatial landscape or scene in which the representation is portraited as an act of embodied visual language or a question about the boundaries of poetic discourse to express thoughts. In a significant evidence of self-consciousness, some of these poets even use terms or concepts taken from neuroscience. Those procedures may be seen as cases of metacognitivism linked to the result a huge neural activity located in the prefrontal cortex. This article explores a cognitive reading of these poems from a neuroscientific perspective, in order to discern new dimensions of metapoetic selfexploration or meta-self-exploratory poetry.

Key words: Poetry; Consciousness; Self-exploration; Cognition.

1. Metodología: el acceso indirecto al «Bloque de arRanQue» o Punto CIEGO CEREBRAL Y LA RELACIÓN ENTRE LA METACOGNITIVIDAD Y LA ACTIVIDAD DE LA CORTEZA FRONTAL

Soy estando y viéndome; viéndome ver y así sucesivamente. Paul Valéry $(1972,32)$

La experiencia, de la que se expondrán varios ejemplos a continuación, es conocida y bastante generalizada; afecta por igual a personas que han permanecido largo rato frente a un espejo, mirándose fijamente a los ojos, y a quienes se han sentado a pensar en sí mismos, intentando llegar hasta el final de sí, con los ojos cerrados y en absoluta concentración. En ambos supuestos, la experiencia acaba en un leve mareo, en un estado borroso de la vista o en una desconexión, de forma que el viajero interior acaba por distraerse o pensar en algo diferente, quizá por la imposibilidad de seguir adelante y llegar al fondo de la propia subjetividad. Como describe Terry Eagleton, hay un «punto ciego» inalcanzable ${ }^{1}$. Estas experiencias, comentadas a veces en familia o entre amigos, son bastante comunes, y el resultado siempre cobra la forma del abandono frustrado. El motivo de esa imposibilidad de llegar a algo parecido al «uno mismo final» lo explica el neurocientífico David Eagleman en su ensayo Incógnito:

Aparte de la falta de acceso, podría darse una prevención del acceso. Mi colega Read Montague especuló en una ocasión que podríamos poseer algoritmos que nos protejan de nosotros mismos. Por ejemplo, los ordenadores poseen bloques de arranque que son inaccesibles para el sistema operativo: son demasiado impor-

\footnotetext{
${ }^{1}$ «En el núcleo del individuo hay un punto ciego que forma parte de él, pero que nunca podría revelarse a la conciencia [...] por la mera autorreflexión. Sería como intentar levantarse uno mismo agarrándose de la trabilla, o verse viendo algo» (Eagleton 2017, 65-66).
} 
tantes para el funcionamiento del ordenador como para que ningún otro sistema de nivel superior encuentre un camino de acceso, bajo ninguna circunstancia. Montague observó que cada vez que intentamos pensar demasiado en nosotros tendemos a «desconectarnos» y quizá se debe a que nos acercamos demasiado al bloque de arranque. Tal como escribió Ralph Waldo Emerson un siglo antes: «todo nos intercepta de nosotros mismos» $(2013,240-241)$.

Este singular bloqueo de acceso puede verse citado también en textos de otro tipo, como filosóficos o literarios. Dentro de los primeros, Ludwig Wittgenstein anota en sus diarios ingleses: «Con mi autoconocimiento sucede esto: si se me colocan encima un cierto número de velos veo todavía claro, a saber, los velos. Pero si se me quitan, de modo que mi mirada pudiera avanzar más hacia mi yo, entonces mi imagen comienza a hacerse borrosa» $(2000,63)$. Y términos similares pueden encontrarse en la novela de Edgar Lawrence Doctorow, Andrew's Brain, donde Andrew piensa en estos términos: «I also have a tin mirror over the sink and I look into it so that someone is there beside me. I have done this because Wittgenstein did it»-es curioso que el personaje comente la experiencia recordando precisamente a Wittgenstein - «He who understood so well the deceptions of the thinking brain. But it is dangerous to stare into yourself. You pass through endless mirrors of self-estrangement. This too is the brain's cunning, that you are not to know yourself» (Doctorow 2014, 1238-1679). Creo que no es baladí apuntar que Andrew, el protagonista que describe en primera persona la imposibilidad de acceso, es neurocientífico. También podemos hallar impresiones similares en el estudioso de la mente Douglas R. Hofstadter ${ }^{2}$ y en un poema de Hans Magnus Enzensberger titulado «Homenaje a Gödel»: «Tú puedes describir tu propio lenguaje / en tu propio lenguaje: / pero no del todo, / Tú puedes investigar tu propio cerebro / con tu propio cerebro: / pero no del todo» $(2002,11)$. Francisco González Fernández, que cita este poema de Enzensberger, lo vincula con el teorema de la incompletud de Gödel, en términos que nos resultan oportunos: «el teorema de Gödel, con sus ideas de autorreferencia y de indecidibilidad, podría indicar por analogía que para alcanzar el grado de abstracción necesario para comprender nuestra existencia, sería necesario salir del propio sistema, lo cual es evidentemente imposible» (2012, 475; más radical, Daniel C. Dennett diría que no hay sistema, en cuanto la conciencia es una ilusión de sistema). Y abandonar el sistema es imposible en un sentido matemático, pero la poesía, al salir del sistema lógico y mirar al ser humano desde otra perspectiva, más pendiente de la decibilidad que de la indecidibilidad, más irracional que racional, acaba por

\footnotetext{
${ }^{2}$ «Era casi como si ese escurridizo fenómeno llamado 'consciencia' se elevara a sí mismo tirando de sus propias orejas; como si se fabricara él solo de la nada y se disolviera otra vez en esa nada cuando uno trataba de examinarlo de cerca» (Hofstadter 2008, 14).
} 
ser el espejo ausente donde la mente puede mirarse y, a la vez, contar y analizar lo mirado. Es la vía, hasta cierto punto, natural de acceso.

Por lo tanto, parece que sí es posible traspasar esa pantalla y arribar al bloque de arranque, al menos temporalmente; lo que sucede es que no puede lograrse pensando del modo convencional. Cabe hacerlo de dos formas: la meditación trascendental, según cuentan los que la han practicado -véase la novela en verso de Andrés Ibáñez El rostro verdadero (2018b, 230-231), o su ensayo Construir un alma (2018a)-, y mediante la literatura, en especial mediante la poesía, porque la poesía, a través de su juego de sentidos y sonidos, parece lograr un tipo de conexión neuronal que diríase capaz de funcionar como salvoconducto y de engañar al propio cerebro, permitiendo un acceso fugaz a lo más hondo de la identidad.

Pero, antes de seguir, debemos comenzar el diálogo de la poesía con la ciencia, aclarando que no usaremos esta última como demostración, sino más bien como punto de apoyo del razonamiento ${ }^{3}$ y como sistema de metáforas muy útil para explicar ciertos momentos en que la poesía reflexiona sobre la conciencia y la percepción de un modo particularmente intenso y concentrado. Desde un pionero artículo de Luján Atienza (2006), queda claro que la perspectiva cognitivista es interdisciplinar y su complejidad invita a hacer un uso cauteloso y no sumario de sus aportaciones. La poesía es una forma de literatura, la literatura es una forma de lenguaje -Andrés Amorós decía que «la literatura es obra de arte hecha con palabras, sin que esto suponga sujeción a ningún criterio estético previo» $(1987,19)$ - y «el lenguaje», como ha escrito el neuropsicólogo Manuel Carreiras, «puede verse como un espejo de la mente que permite reflejar las propiedades esenciales de ésta» (1997, 10-11); además, la literatura es un lenguaje representativo y Carreiras recuerda que «Bickerton $[\ldots]$ considera al lenguaje primordialmente como un sistema de representación, es como una lámina de vidrio transparente a través de la cual cualquier objeto concebible en el mundo nos parece claramente visible» (1997, 11). Lo que recuerda el aserto de Mark Turner en Reading Minds (1991): "La literatura vive dentro del lenguaje y el lenguaje dentro de la vida diaria. El estudio de la literatura debe vivir dentro del estudio del lenguaje, y el estudio del lenguaje dentro del estudio de la mente cotidiana» (en Luján Atienza 2006, 18). Turner, como Spolsky y Tsur, mantiene una visión de la relación entre la literatura y la mente desde una perspectiva cognitiva formal y centrada en la comprensión del texto, frente a otros enfoques más preocupados por las dimen-

${ }^{3}$ Es decir, de las tres posibilidades de relación entre ciencias cognitivas y literatura planteadas por Karin Kukkonen «Some critics might study literature through the scientific method of experiment and statistical analysis, others might embed the results of the cognitive sciences in their interpretations, and still others might explicitly seek to outline the conditions of a dialogue between the sciences and the humanities» $(2017,22)$, nuestra postura fluctúa entre las dos últimas, tomando elementos de ambas. 
siones biológicas de las sensaciones de lectura y emociones recogidas en los textos. Una perspectiva que entendemos adecuada al asunto central de este trabajo, que no es otro que la poética metacognitiva.

Si partimos de la complejidad del proceso cerebral que permite al ser humano ver el exterior - por más que resolvamos sus numerosos mecanismos y combinaciones en menos de un segundo-, podríamos decir que el lenguaje es el intento de volver transparente aquello que las limitaciones de nuestra percepción visual habían opacado, dando la razón al Juan Ramón Jiménez que vindicaba en el poema que abre Animal de fondo «la transparencia, dios, la transparencia» $(1959,1290)$, como objetivo último del poema. El poema reconstruye la realidad y la experiencia, incluso aquella que no se ha tenido. Y esa voluntad reconstructora es similar a la que lleva a cabo el propio cerebro al percibir, como nos dice el neuroquímico Jean-Pierre Changeux: «No hay, pues, percepción "absoluta", sino una reconstrucción del color, como, de manera general, del mundo exterior, por el cerebro» (2010, 98-99). La poesía es, en consecuencia, la reelaboración de una reelaboración.

$\mathrm{Si}$, resumiendo de forma algo intolerable e injusta, la narrativa «cuenta», podemos decir que la poesía «ve». Amelia Gamoneda recuerda las teorías neuroestéticas de Zeki (2009) sobre la relación entre la visión y el arte desde la ciencia : «si la fonction de la part visuelle du cerveau est l'acquisition de connaissance sur le monde environnant, l'art-Zeki parle essentiellement de la peinture- constitue une extension de la fonction de cette partie du cerveau» (Gamoneda 2017, 25). En tanto activación de algunas partes del cerebro -bastantes, como demuestran los complejos diagramas sobre la visualización y la contemplación de obras de arte que Eric R. Kandel incluye en su monumental tratado $(2013,405,445)$-, la percepción visual supone una intensificación del trabajo de ciertas áreas, cuyo rastro eléctrico y energético puede seguirse con los instrumentos adecuados, lo cual no hay que entender como demostración, sino como acercamiento fiable a una concentración de conexiones neuronales. Entre estas áreas involucradas se ha señalado especialmente la activación de la corteza prefrontal del cerebro (Chávez 2004, 41; Zeki 2009, 53; Rendón 2009, 127; Armstrong 2013, 37), lo que no hay que entender en el sentido de que la auto-percepción suceda tan solo ahí, pues el cerebro piensa como sistema organizado 4 y razona mediante analogías (Hofstadter 2008, 53), de forma que hay que precisar que la percepción del yo sucede preferentemente en esa área de la corteza prefrontal (Dehaene 2018, 103), o en un sistema donde la corteza prefontal tiene un papel predominante ${ }^{5}$. Los estudios son claros a este respecto,

${ }^{4}$ Véanse Kuffler y Nicholls (1976), Pinker (2003, 72), o Eagleman (2017, 118); para Dennett, el cerebro se autorregula como un «mercado libre» $(2017,161)$; para Searle es un «campo unificado», según explica en Blackmore (2010, 276).

5 Sostener que la conciencia reside exclusivamente ahí constituiría una forma intolerable de dualismo. Como ha señalado agudamente Roger Bartra, la existencia de una zona del 
como apunta Dehaene -después de citar unas líneas visionarias del filósofo Avicena que apuntaban en la misma dirección-: «prefrontal neurons are massively multimodal», dice el psicólogo cognitivo francés, quien añade que esas neuronas «exhibit a remarkable capacity to remain active even after the perceived object has vanished», $\mathrm{y}$, sobre todo, que: «Prefrontal regions participate in a brain scale network whose activity constantly fluctuates, even in the absence of any sensory inputs. It is tempting to associate this fluctuation with the spontaneous flow of consciousness and imagination» (Dehaene 2009, 321), además de tener una incidencia clara en la interpretación de situaciones o estímulos ambiguos (Goldberg 2009, 102). En consecuencia, el momento de creación de un poema debe originar un esfuerzo neuronal en esa área cuando toca a la vez situaciones ambiguas, creativas y metacognitivas, como lo hacen los poemas que luego veremos; en esos casos, la activación lingüística literaria debe suponer una extensión y una intensión de esa función cerebral. Por ello, denominaremos hiperfrontalidad a la característica que parecen tener algunos poemas contemporáneos en los que se advierte una especial conciencia de la conciencia del poeta - de «metaconciencia» hablan Beecher $(2016,300)$ y el neurólogo Vilayanur Ramachandran (en Blackmore 2010, 261), aunque dentro de marcos conceptuales diferentes ${ }^{6}$-, ligadas a su capacidad de protección y de pensamiento abstracto, convertidas en uno de los principales asuntos del texto. Vamos a explicar de dónde partimos para acuñar el término hiperfrontalidad. Para el neurólogo David Eagleman hay algunos supuestos de baja concentración, denominados por el autor «estados de flujo», en los cuales «el cerebro entra en una especie de hipofrontalidad, que significa que las partes de la corteza prefrontal pierden temporalmente la actividad. Son las áreas que participan en el pensamiento abstracto, en la planificación del futuro y cuando nos concentramos en nuestra propia persona» $(2017,109)$. La hiperfrontalidad, en consecuencia, tendría lugar en el caso opuesto, es decir, cuando nos hallemos ante una activación extraordinaria de las funciones lingüísticas y de concentración

cerebro encargada de crear una sensación de identidad supondría una visión dualista no muy distinta de la cartesiana, puesto que convertiría en cuerpo al resto del cerebro y en espíritu a la supuesta zona al mando: «Es sintomático que Gazzaniga tenga la necesidad de suponer la existencia de un aparato neuronal traductor e interpretador ubicado en la corteza cerebral izquierda, encargado de generar la ilusión de una conciencia individual coherente? ¿No se trata de una nueva visión dualista que ha sustituido al viejo homúnculo con un mecanismo interpretador?» (Bartra 2007, 51).

${ }^{6}$ Husserl también se planteó el problema de la conciencia en capas o niveles, para alejar el problema conceptual de una especie de mise en abyme de la conciencia en relación con su capacidad perceptiva y autoperceptiva; véase Osswald $(2014,45)$. A modo de curiosidad, traigamos a colación que en su novela La búsqueda del absoluto (1834), Balzac incluye estas líneas sobre la denostada frenología de Franz J. Gall, en la descripción del personaje Baltasar Claes: «Su ancha frente ofrecía, por lo demás, las protuberancias en las cuales ha situado Gall los mundos poéticos» $(1966,289)$. 
en la propia persona, o en la propia percepción, al mismo tiempo. Según Eagleman, la «corteza prefrontal medial (CPFm)», es esa región del cerebro «que se activa cuando se piensa en uno mismo» (2017, 25; véase también Harris, Lee y Capestany 2014, 1000), de forma que es natural que se active cuando uno piensa en sí mismo pensando, tanto más cuando según la opinión de un estudioso de esa zona concreta, Goldberg (2009), la prefrontal es la zona que lidia con las ambigüedades semánticas, hermenéuticas y perceptivas -características de cualquier poema digno de llamarse metacognitivo-.

\section{BREVES ANTECEDENTES DE LA HIPERFRONTALIDAD POÉTICA Y ALGUNOS EJEMPLOS EN LA POESÍA ESPAÑOLA CONTEMPORÁNEA}

La esfera de la poesía no se encuentra fuera del mundo, cual fantasmagórica imposibilidad propia de un cerebro de poeta...

Nietzsche $(2016,97)$

A continuación veremos una serie de poemas en los que sucede algo parecido a Las Meninas, tal como las describiera Michel Foucault y las explicase el filósofo Stuart Hall. Del mismo modo que en el texto foucaultiano, en estos poemas que examinaremos los poetas, como los personajes de Velázquez, «parecen sentados en la posición desde la cual les estamos mirando» $(1997,58)$, siendo a la vez (pintor y poetas) objeto y sujeto de la obra. El poeta integra en su visión al lector, que mira desde el mismo lugar que mira el poeta -quien, a su vez, está viéndose mirar o percibiéndose percibiendo-, de forma que se cumple la unión de semántica y pragmática, en los términos señalados por Luján Atienza, pues es uno de los pocos casos en que el lector «tiene acceso a la situación de escritura» $(2006,30)$, no tanto a la física -esto es, el entorno y la postura física del momento de generación, que son los fenómenos en los que Luján centra su estudio-, como a la situación de escritura mental, al estado mental que tiene el yo poético supuestamente en el momento en que redacta el poema, que funciona como «escena extendida» (Luján Atienza 2006, 33) de metacognitividad. Sucede en estos casos, que rozan lo que Javier Maderuelo ha denominado «paralelismo sinestésico entre ojo y pensamiento» (en Benéitez 2019, 111), lo mismo que al personaje antes citado de Doctorow: en el «momento» de lectura del poema, hay alguien junto al lector en el espejo, una especie de duplicación subjetiva autoscópica que constata su percepción: escritor y lector se superponen, sin dejar de ver al escritor, de la misma manera que en Las Meninas no dejamos de ver el autorretrato de Velázquez mientras contemplamos holísticamente el cuadro. «El reflejo, la imagen, el doble desdobla aquello que duplica», dice Derrida, «puesto que lo que es reflejado se desdobla 
en sí mismo y no sólo porque se le adicione su imagen» $(1978,48)$. En la imagen de un poeta que se piensa pensando hay un espejo -Hofstadter (2008, 14) asocia la conciencia al azogue-, y un reflejo, y un sujeto desdoblado, alguien que ha convertido su identidad en un campo de operaciones para la reflexión, en un juego de espejos para el pensamiento ${ }^{7}$. De las dos grandes líneas que tendría -resumiendo grosso modo- la imaginación poética, una consciente en el sentido racional y otra de consciencia vidente, que «no necesita tanto una plenitud de conciencia como una alteración, un traspasar esa conciencia» (Méndez Rubio 2016, 74), la hiperfrontalidad metacognitiva lírica suele formar parte de la primera línea de actuación. César Aira, un pensador y novelista muy atento a la creatividad y a las peripecias de la imaginación, escribe en su novela Entre los indios: «Había un ritmo, que alternaba precipitaciones vertiginosas en las que las ideas se encadenaban unas con otras tan rápido que pasaban como visiones fugaces por su lóbulo frontal» $(2012,98)$.

José María Castrillón ha señalado una plausible fecha de nacimiento de la percepción poética autoconsciente como tema o motivo de fondo del poema; lo ubica en el verano de 1798, cuando William Wordsworth escribe «Lines Composed a Few Miles Above Tintern Abbey», un texto canónico ${ }^{8}$ que «propone uno de los cambios más significativos para el discurrir de la poesía occidental»; para Castrillón, el cambio consiste en que el antiguo canto de las maravillas de la naturaleza se embebe o engloba dentro de algo nuevo: un canto a la maravilla de cantar: «la maravilla está en contemplar», sostiene, pues los versos «celebran la potencia de la visión y de la imaginación humanas tanto como cantan a la naturaleza» (Castrillón 2018, 10). Mientras los Lied populares coetáneos, recogidos por Achim von Arnim y Brentano entre 1806 y 1809 en tres volúmenes, contraponían, a juicio de Schopenhauer, la conciencia del yo cantante con - o contra- su emoción amorosa, la poesía culta de la época parecía optar por el primer fiel de la balanza. Schiller, en 1796, al explicar la diferencia entre poetas ingenuos y sentimentales, dice de este último tipo: «Él medita en la impresión que le producen los objetos, y sólo en ese meditar se funda la emoción en que el poeta mismo se sume y en que nos sume a nosotros») $(1962,85)$; en palabras de Nietzsche en El nacimiento de la tragedia -que había explicado en páginas anteriores la hipótesis de Schopenhauer, en el capítulo dedicado al poeta lírico-, la esencia creadora «de manera maravillosa [...] puede dar la vuelta a los ojos y mirarse a sí misma; ahora él es a la vez

${ }^{7} \ll \ldots$ art and cognition have always stood as two convex mirrors each reflecting and amplifying the other. Yet surprisingly, in spite of monumental recent developments in both aesthetics and cognition, the connection between the two disciplines has not been studied systematically» (Solso 1996, xiii).

${ }^{8}$ Para M. H. Abrams, este poema sigue «el ejemplo de Frost at Midnight [...] de Coleridge», y opera una «metafísica de la interacción sujeto-objeto» $(1992,86)$ paralela a la de los sistemas filosóficos poskantianos. 
sujeto y objeto, a la vez poeta, actor y espectador» $(2012,81)$. La mirada del poeta se vuelve consciente de sí y esa autoconsciencia se torna tema o fondo temático del poema. Por parafrasear los conocidos términos de M. H. Abrams (The Mirror and the Lamp, 1953), en el Romanticismo la lámpara también podía servir para alumbrar a la figura reflejada en el espejo. En ese sentido, la imagen nietzscheana de girar los ojos y mirar hacia dentro nos resulta especialmente válida: llevándola a la literalidad biológica, en tal caso el poeta miraría parte de la sección frontal de su propio cerebro. Sin saberlo, Nietzsche apuntaba correcta y científicamente al lugar exacto donde nace el poema autoconsciente. La poesía moderna, dentro de un giro hacia la «individuación» que «está en la base de toda la producción lírica desde el Romanticismo hasta las vanguardias» (Pradel 2018, 60, a partir del concepto de «individuazione» de Guido Mazzoni), privilegiando la percepción personal del sujeto -tanto del yo poético como del sujeto en sí-. Estos antecedentes románticos perduran en el tiempo, por cuanto, según Luis Ángel Abad, «no es desacertado afirmar que la identidad contemporánea se construye sobre un patrón romántico de la identidad que permanece intacto» $(2002,41)$. Por estos motivos, y por otros relacionados con las expectativas de lectura ${ }^{9}$, importa saber la fecha aproximada de composición de los poemas, sobre todo cuando aluden a la conciencia, pues el acervo científico de cada época encarna distintos fenómenos bajo expresiones como «yo», «alma», «conciencia», «espíritu» o «identidad», algo especialmente significativo para interpretar adecuadamente poemas en los que el eje discursivo está planteado desde la mayor autoconciencia epistemológica, esto es, desde el conocimiento fehaciente de qué significa ser, ser consciente y ser uno mismo, en cada época.

En los poemas metacognitivos o hiperfrontales no deben bastarnos los usos similares de algunas palabras y estructuras; como apunta Searle, será necesario también, como en cualquier otro proceso mental, conocer «los apoyos causales de la conducta» $(1996,36)$. Y parece lógico pensar que el principal apoyo causal en este caso es la tradición; esto es, la existencia de un corpus canónico de poemas que hacen que el poeta se vertebre en una tradición reconocible, que hace del poema su espacio de pensamiento. Y es una tradición de largo alcance: aunque el sabio hindú Jnaneshvar, traducido por Jesús Aguado, sostiene en unos versos que «El conocimiento no puede conocerse a sí mismo. / El que percibe no puede percibirse a sí mismo» $(2013,18)$, la poesía occidental pare-

9 «Trying to make sense of a poem without knowing when it was written or by whom can be extremely difficult, because one is deprived of likely hypotheses to test about how to connect its parts. Learning the artistic conventions that prevailed during a particular period or having an acquaintance with an author's other works may not provide automatic comprehension of a text, because the construction of meaning still requires to-and-fro adjustments between the details of the work and the configurations one expects (and may or may not find)» (Amstrong 2013, 55). 
ce defender justo lo contrario, la factibilidad del autoexamen, el acceso al bloque cerebral de arranque. «La poesía debe ser algo más que una concepción de la mente. Debe ser una revelación de la naturaleza. Las concepciones son artificiales. Las percepciones son esenciales» $(1987,27)$, escribió el poeta estadounidense Wallace Stevens en Adagia. Son frecuentes las menciones de Stevens a la mente, a la conciencia, al proceso de pensamiento, en este libro de aforismos y fragmentos, pero también su poesía explicita los procesos donde la poesía se vuelve percepción de la percepción, esos instantes en que el acto de pensar se vuelve visible en el poema. En Notes Towards a Supreme Fiction (1942), Stevens escribe (1996, 17):

Empieza, efebo, por percibir la idea

de esta invención, este mundo inventado,

la inconcebible idea del sol.

Debes hacerte de nuevo un hombre ignorante

y ver con ojo ignorante el sol de nuevo

y verlo claramente en la idea de sol.

Nunca supongas que una mente inventora es la fuente

de esta idea ni compongas para esa mente

un voluminoso dueño envuelto en su fuego.

Algunas de estas ideas están claras en Adagia; así, en su reflexión número 114, anota Stevens: «Tal vez haya un grado de la percepción en el cual lo que es real y lo que es imaginado sean una sola cosa: un estado de observación clarividente accesible o potencialmente accesible al poeta o, digamos, al poeta más agudo» $(1987,28)$. Número 130: «La lengua es un ojo» $(1987,30)$. Número 140: "Tenemos que entrar con audacia en el mundo interior del hombre o no entrar en absoluto» $(1987,32)$. En el número 212 vuelve al tema de la resistencia al acceso al bloque de arranque: «... la mente es la fuerza más terrible del mundo precisamente en esto, en ser la única que puede defendernos contra ella misma. En esta noción se basa el mundo moderno», y 213: «El poeta representa la mente en el acto de defenderse contra sí misma» $(1987,36)$. Stevens sería uno de los tres puntales de la poesía metacognitiva; el segundo poeta hiperfrontal canónico, en el que no podemos detenernos por razones de espacio, sería el John Ashbery de «Autorretrato en un espejo convexo» ${ }^{10}$. Pero el caso de poema canónico metacognitivo más conocido vamos a verlo a continuación.

10 «Ashbery, como poeta, se ve obligado a presentarse como si fuera solamente una parte mutilada de un todo ya mutilado. No tengo la capacidad actualmente para explicar por qué la mayoría de los poetas fuertes de nuestra tradición, desde Wordsworth a nuestros días, manifiestan ese masoquista impulso de representación, incluso mientras se esfuerzan por retraerse de las ironías iniciales» (Bloom 2003, 38, énfasis del original). 


\section{EJEMPLIFICACIÓN EN POEMAS CONTEMPORÁNEOS}

Devano el pensamiento, sus imágenes.

Basilio Sánchez $(2008,56)$

Aunque nuestro objetivo es centrarnos en la poesía española contemporánea, para llegar a ella contextualizadamente partiremos de un conocido poema de Emily Dickinson, el número 598 (en la edición de R. W. Franklin) ${ }^{11}$, que vamos a leer en la traducción de Rolando Costa Picazo (2011, 159):

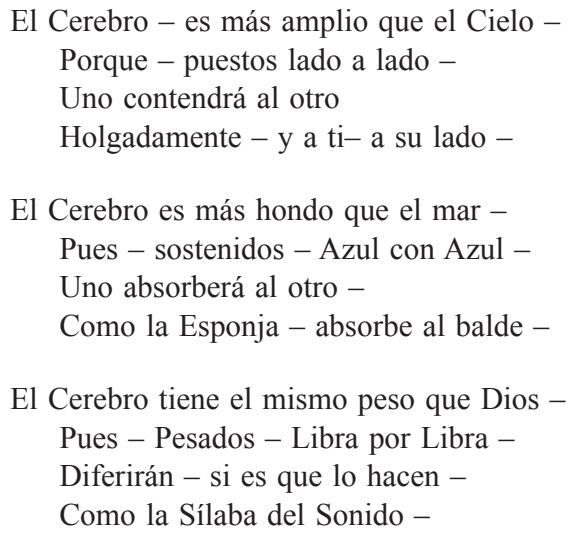

Este poema, que ha sido traducido también por poetas españoles actuales como José Luis Rey o Lorenzo Oliván, constituye uno de los puntales en los estudios sobre cognición y poesía. Como expresa Sabine Sielke, quien ha escrito un inteligente comentario sobre este poema desde un acercamiento crítico cognitivo, el hecho mismo de la percepción es para Dickinson un beneficio valioso en sí mismo, que constituye la motivación recurrente de muchos de sus poemas $^{12}$. En este caso la «mirada» del poema se proyecta nada menos que

${ }^{11}$ Este es el poema original: «The Brain-is wider than the Sky- / For-put them side by side- / The one the other will contain / With ease-and You-beside- / The Brain is deeper than the sea- / For-hold them-Blue to Blue- / The one the other will absorb- / As Sponges-Buckets-do- / The Brain is just the weight of God- / For-Heft them-Pound for Pound/ And they will differ-if they do- / As Syllable from Sound-》 (Dickinson 1997, 133).

12 «Dickinson's poem 'The Brain -is wider than the Sky-' (Fr598) not only insists on the immense scope of our mental universe, on a magnitude that 'pain' may easily reduce to 'The minute Circumference / Of a single Brain' [...] by resisting the term mind and privileging the word brain; the poem also insinuates that these mental spaces evolve from neurophysiologic processes. Based on what Roland Hagenbüchle calls 'phenomenological reduction'-a focus not so much on things and phenomena themselves, but on how they affect our body and mind -many of Dickinson's poems are preoccupied with physiological operations and, more significantly, with the disruption and failure. Loss of consciousness, paraly- 
hacia el cerebro, espacializándolo, convirtiendo sus inacabables circunvoluciones en una suerte de paisaje marítimo. Por este motivo, no sería del todo desacertado utilizar la metáfora del «pensamiento-paisaje» de Michel Collot, tan y como Víctor Bermúdez la ve aplicable para la poesía del francés Lorand Gaspar (cfr. Bermúdez 2017, 41), como un conjunto de marcadores fenomenológicos que acaban explicando procesos perceptivos y cognitivos de la persona que escribe -Sielke habla en su texto sobre Dickinson de «reducción fenomenológica»-. Al explicar el paisaje como un acto perceptivo, Gaspar acaba presentando su pensamiento también como un espacio - un paisaje- que cobra su propia sensorialidad, su estética, y por lo tanto el poeta lo ve y lo lee como un paisaje describible, aprehensible por los sentidos y por el raciocinio lingüística y literariamente expresado. Bermúdez reproduce unos versos de Gaspar: «pensée arrête-toi et accueille / cet instant de fraîcheur / que ton corps compose avec la terre», que traduce como «detente pensamiento y acoge / este instante de frescor / que tu cuerpo compone con la tierra», explicando que en ellos «el yo lírico atestigua una adherencia a la naturaleza que obstruye el pensamiento y que propicia una comunión estrictamente sensible», que «necesariamente se auxilia de la especificidad del lenguaje botánico de la naturaleza» (Bermúdez 2017, 43). Pero, ¿qué sucede cuando el yo lírico elige su propia mente como espacio? Pues en tal caso la metáfora del conocimiento-paisaje llega a su máxima expresión, como sucede en este poema de Antonio Cabrera $(2016,71)$ :

\section{ESPEJO DE LA CONCENTRACIÓN}

Las veces en que todo se reduce a sólo lo que importa, oigo un zumbido cerca pero lejos.

Las palabras

eligen camuflarse en los objetos

-de impronunciado corazón- y así consiguen envolverme; convertidas en quieta nebulosa, muestran su espalda, denegadas, yermas. Sólo tú, mente, prendes. Con gran gesto de ardor embebecido manipulas tu médula concisa.

Lo que te ha concentrado, esa entraña

que te lleva hacia sí, construye un cerco

con capas repetidas, con vitrales

deslucidos: el muro de palabras

que supiste acallar. Me asomaré.

Veré tu esfuerzo y me veré asomado.

sis, pain, and the limits of perception are central to her poetry and poetics-a poetics that explores the lacunae and gaps of cognition and exposes the brain's capacity to break down information and remember experiences and sense impressions in a highly selective and associative manner. Thus, even if 'Perception of an object costs / Precise the Object's loss-,' as Dickinson puts it, 'Perception in itself' comes out as 'a Gain' and a recurrent motivation of many of her poems» (Sielke 2008, 69). 
Algunas palabras («cerca», «lejos», «lleva hacia», «cerco», «muro») evidencian la conversión del pensamiento en espacio, en paisaje recorrible. Y al utilizar la segunda persona, «solo tú, mente, prendes», Cabrera instituye un diálogo con el otro machadiano que siempre va consigo, su pensamiento, canalizado en ese «tú» que es característico en otras obras de autoexamen, como las autobiografías de Juan Goytisolo, también escritas en segunda persona, y también ellas mismas análisis y autocuestionamiento de la identidad. El poeta describe la escena extendida a la que antes aludíamos de autorrepresentación, centrándose en los aspectos cognitivos y enunciativos de la misma, amparándose en el motivo autorreflexivo e «instrumento filosófico por excelencia» (Paz 1990, 214): el espejo.

Pero la primera persona suele ser el procedimiento retórico ideal para ese sistema perceptivo intensificado. Un ejemplo es este poema de Erika Martínez, donde la poeta andaluza lleva cabo un inteligente ejercicio de reflexión identitario-perceptiva $(2017,14)$ :

\section{ABOLIRSE}

Se podría afirmar: yo soy mi cuerpo.

Sin embargo, si perdiera la pierna derecha en una batalla o huyendo de la batalla o más bien en un estúpido accidente doméstico, seguiría siendo yo.

También seguiría siéndolo si perdiera las dos piernas, o incluso todos mis miembros.

¿Cuánto cuerpo tendría que perder para dejar de ser yo?

Quizás una mínima parte de mí representaría al resto por sinécdoque. O quizás mis restos me convertirían en otra.

Cortarte las uñas te modifica existencialmente.

Metapoética y metacognitividad se anudan en este poema, donde la extensión de los versículos parece remedar la elongación de las digresiones, y donde el encuentro con la identidad parece más bien enfocado a las posibilidades de su abolición. En este sentido, David Eagleman responde a una de las preguntas de la autora, respecto a cuánto puede seccionarse uno y seguir conservando identidad: «se observa en gatos a los que se ha extirpado gran parte del cerebro, y que sin embargo pueden seguir caminando normalmente sobre una cinta: los complejos programas que participan en el modo de andar quedan almacenados a un nivel inferior al del sistema nervioso» $(2017,16)$. Esta pregunta de cuánta amputación permite el yo se la han formulado también Marta Agudo en un poema de Sacrificio $(2021,56)$, y algunos narradores ${ }^{13}$. Es decir,

${ }_{13}$ Así se expresa un personaje femenino de Germán Sierra en su novela The Artifact $(2020,42)$ : «Me estaba preguntando cuánto se podría transformar mi cuerpo sin dejar de ser yo para otros». Un personaje secundario de Noche y océano de Raquel Taranilla $(2020,70)$, dice, arrogándose la voz de Trelkovsky -el inquietante protagonista de El quimérico inquilino de Topor-: «¿A partir de qué momento el individuo deja de ser aquello que se entiende como tal? Me arrancan un brazo, muy bien. Entonces digo: yo y mi brazo. Me arrancan los 
depende de que la identidad sea considerada solo como consciente o como la suma de consciente e inconsciente -como lo harían Jung y Freud, o Eric R. Kandel desde la perspectiva neurocientífica-, en cuyo caso, y mientras quede un átomo de nosotros dotado de nuestro $\mathrm{ADN}$, en él van inscritas nuestras Señas de identidad -por utilizar el título de Goytisolo- y la escritura reptiliana y evolutiva presente en nuestro ácido desoxirribonucleico. Hay otro poema, «Talleres», donde Erika Martínez hace una referencia que parece hiperfrontal:

La creatividad está en el área de trabajo del cerebro. Lo descubrieron en un laboratorio neoyorkino, donde a una niña que imaginaba una oveja con cabeza de lobo se le iluminó el córtex prefrontal $(2017,71)$.

En estas líneas se advierte claramente la metacognitividad, puesto que en el acto de creación se está explicitando el origen cerebral de la creatividad poética, creando un bucle (Hofstadter 2008) conceptual que, además, alude de forma explícita a la frontalidad.

Olvido García Valdés, uno de los nombres más significativos de la poesía española contemporánea, incluye en su obra elementos reflexivos relacionados con la experiencia de la escritura y el pensamiento. Filósofa de formación, sus preocupaciones ontológicas y las poéticas encuentran feraces hilos de conexión en la retícula de sus poemas. Así comienza, como muestra, uno de los poemas de caza nocturna (1997): «Sólo lo que hagas y digas / eres, incierto lo que piensas, invisible / lo que sientes dentro de ti. / ¿Qué significa / dentro de ti? Nada eres si, como dicen, / no es intersubjetivamente comprobado» (2008, 149). En una de sus poéticas, la autora es consciente de que «Interior y exterior son categorías, metáforas espaciales no estancas [...] sólo podemos percibirnos percibiendo» $(2008,437)$, de lo que suelen ser testimonio alguno de sus poemas más meditativos y autoscópicos, especialmente a partir de $Y$ todos estábamos vivos (2006). En una entrevista, García Valdés recalca el extrañamiento al pensar sobre el pensar: «con el habla pasa lo mismo: no pensamos en ella, fluye de modo natural y sin conciencia, pero a veces [...] la percibimos, y observamos sus mecanismos y procesos, qué raro es eso tan natural, pensar y hablar, qué frágil y quebradizo» (en Agudo 2009, 84). Es decir, estamos ante una poesía metacognitiva, «que se propone a sí misma como escena especular que refleja el gesto poético que la engendra» (Gamoneda 2016, 64), en sintonía con el modo en que «la conciencia es la manera en que millones de células se ven como un todo unificado, el modo en que un sistema complejo se pone un espejo ante sí mismo» (Eagleman 2017, 118). La metacognitividad entendida como un juego de espejos de un juego de espejos, si se permite la imagen.

dos, y digo: yo y mis dos brazos. [...] Pero si me cortan la cabeza: ¿qué podría decir? ¿Yo y mi cuerpo, o yo y mi cabeza? ¿Con qué derecho mi cabeza se arrogaría el título de 'yo’?». 
El poeta Daniel José García incluye en Coma (2008) un poema del que rescatamos estos versos: «El pequeño caimán de la conciencia / se enrosca en la oquedad / de mi cerebro; / no intentes despertarlo» $(2008,49)$, aunque, en puridad, el poeta ya lo ha despertado y la conciencia escribe sobre sí, figurándose dormida. En otros márgenes de autoconciencia debemos incluir el breve poema «Mientras», de la andaluza Virginia Aguilar Bautista $(2010,75)$ :

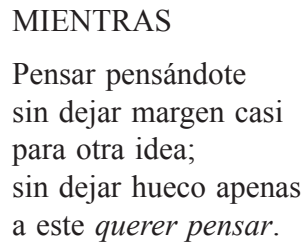

La representación de la percepción se mezcla en él con la percepción de la representación, recordando que «los mecanismos representacionales se piensan de modo que la percepción es en sí misma una herramienta de la acción», como apunta el escritor Iván Méndez González (2017, 325). Es difícil saber si es el objeto el que se convierte en sujeto o viceversa en el poema de Aguilar Bautista, y seguramente lo que le interesa a la poeta es el bucle, el circuito cerrado de representatividad entre uno y otro, que persigue más la apertura que la clausura conceptual. En Dime qué (2011), David Leo García incluye un ambicioso poema fragmentario, «Todos los hombres, todas las memorias», que aborda varios temas, entre ellos el de la identidad confusa que anda en pos de sí misma. Uno de los fragmentos reza de este modo (García 2011, 64):

Y ahora tendría que decir «No soy el mismo nunca soy el mismo» ¿y cuál de mis amigos me creería? Ya, pero aquí estoy, cansado de ser hombres simultáneos.

Para García, la operación de mirar(se) es parecida a la de «habitar un país viéndolo desde lo alto» $(2011,64)$, con la conciencia de «Ser múltiple perdido entre lo múltiple» $(2011,65)$, porque «una neurosis piensa en ti» $(2011,66)$. El proceso poético de la observación de la identidad es entendido como un gesto de neurosis, esto es, de «enfermedad funcional del sistema nervioso caracterizada principalmente por inestabilidad emocional», según el DRAE. La multiplicidad subjetiva, un tema habitual en la poesía española contemporánea (Mora 2016, 121-131), supone un regreso a la concepción homérica del sujeto, explicada por el neurobiólogo Antonio Damasio gracias a la Ilíada y la Odisea: «Los hombres de la Ilíada, por ejemplo, no hablan de su cuerpo como un todo (soma), sino de partes del mismo, a saber, las extremidades» $(2010,153)$, considerándose por entonces que las pocas fuerzas unitarias se referían a la psyché, que era supracorporal. El poema de David Leo García regresa, en cierto modo, a esa concepción atomizada y borrosa, que entiende que la identidad solo pue- 
de estar unida artificialmente por una fuerza, la del discurso, conminada al tiempo a negarla. En su libro posterior, Nueve meses sin lenguaje (2018), García retorna al tema de la desintegración subjetiva, en conexión con el asunto del lenguaje, ya desde el título del poemario. Hay varias alusiones a los procesos cognitivos, como «cerebro suntuosa catedral vacía» $(2018,54)$, o: «Toda conversación odio fraterno, / Broca y Wernicke son Caín y Abel» $(2018,23)$, donde se nombran reveladoramente las áreas cerebrales responsables del lenguaje y la comunicación oral. El poeta, además, brinda alguna imagen de clara afinación: «El sistema nervioso / parece el garabato de un demente» $(2018,52)$. El resultado es un libro autoconsciente de ser operación de lenguaje dirigida al entendimiento de la realidad como exterioridad y del «ser exterior» $(2018,44)$ como forma de estar y ser en el mundo, en el que David Leo García demuestra además de forma explícita sus lecturas de ciencia en general y neurociencia en particular.

Otro supuesto de poesía metacognitiva sería el poema de María Alcantarilla «Visiones de futuro» $(2017 \mathrm{a}, 52)$ :

\section{VISIONES DE FUTURO}

En la distancia gris donde no oigo $\mathrm{mi}$ voz ni escucho al mundo gritarme sin cansancio el error que es convertirme en lo que niego, tal vez ahí pueda cambiar de nombre o reescribirme como si todo no hubiese terminado.

Pero después estoy yo y están mis dudas y el tránsito infinito hacia un futuro apenas realizable mientras alguien camina hacia mi nombre con la astuta certidumbre de devolverme de nuevo hacia el vacío.

Tal vez si comprendiera, si pudiera comprender toda esta vasta materia cuya forma es mi forma pero encarna un débil parecido con el odio, qué digo, con la muerte de vestida de persona, quizá sí la podría abrazar y desmentirle que no tenemos tiempo.

Quizá, si comprendiera, podría regresar hasta esta voz y describirla al fin y ser su cuerpo.

La edad de la ignorancia, el singular poemario de Alcantarilla donde se contiene esta pieza, está construido a partir de un epígrafe de Pessoa donde ya se apela a la construcción de la máscara poética desde el fingimiento del poeta portugués - una constante en la poesía española de finales del siglo XX y principios del siglo XXI, como observamos en otro lugar-, y parte de un sin- 
gular presupuesto, el uso de un yo poético masculino en la mayoría de los poemas, pese a ser una mujer su autora. El ejercicio de desdoblamiento $-\mathrm{y}$ de transgenerización - tiene su correlato en una reflexión constante sobre el nombre y posibilidad de representar (otro de los poemas se titula «No puedo ser nombrado»), y en «Visiones de futuro» llega a su cenit la preocupación por la capacidad del poema de encarnar un discurso y una subjetividad (otra) al mismo tiempo. El poema se hace hiperconsciente y desenmascara su proceder al mismo tiempo que enmascara al sujeto desdoblado que lo pronuncia/representa, como intentando demostrar que el único acercamiento honesto a una presentación del yo es enfatizar lo que de presentación tiene ese gesto; es decir, lo que tiene de artificio, de procedimiento poético. Merece la pena señalar que en una novela publicada por Alcantarilla casi a la vez que La edad de la ignorancia, titulada Un acto solitario (2017b), la protagonista cita un trabajo neurocientífico sobre las neuronas Cubelli, más conocidas como neuronas espejo, supuestamente escrito por Joseph Murphay -de quien no hemos encontrado referencia, quizá sea un disfraz del escritor de autoayuda Joseph Murphy, que tiene libros pseudocientíficos sobre el poder de la mente-, del que destacamos la última parte: «Murphay llama a la ínsula el asiento de la conciencia, ya que reúne gran parte de los pensamientos, intuiciones, sentimientos y percepciones», añadiendo - quizá con un recuerdo a la creatividad artística- que «ambas zonas, según los resultados, mostraban una amplísima diferencia, respecto a funcionamiento, entre las Personas con Alta Sensibilidad y el resto de personas») $(2017 b, 73)$. Lo cual demuestra que la autora, como Erika Martínez o David Leo García escribe con plena conciencia del funcionamiento de los sistemas representacionales del cerebro.

Una de las cuestiones paralelas que abre la metacognitividad es su relación con el realismo. ¿Son imaginativos los poemas que describen estados cerebrales, o son testimonio preciso o registro de una sucesión cognitiva? La cuestión se complica si recordamos la perspectiva junguiana: «Un proceso psíquico es algo realmente existente, y un contenido psíquico es tan real como una planta o un animal» (Jung 2002, 436). Por lo común, los autores sitúan el ámbito fenoménico de observación dentro de la esfera más propicia para estas reflexiones, la del lenguaje, por cuanto tenemos como humanos la sensación de que parte del pensamiento es un discurso que escuchamos en nuestro interior (Roessler 2016; para George Steiner, «I establish and preserve my experience of self by a stream of internalized address», 1972, 72). Veamos al efecto este representativo poema de Tomás Segovia $(2005,17)$ :

\section{REVOLVIENDO}

A favor de qué orden contuso y maniatado

Hemos perdido fuerza y prontitud

Mi mundo y yo para ir a nuestras citas 


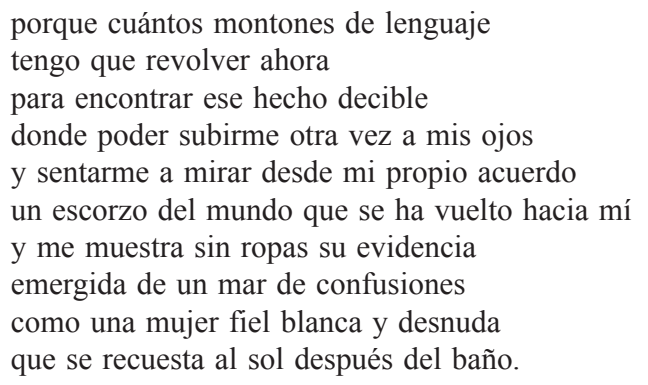

La parte somática de estas descripciones tiene su lógica porque el ser humano piensa con todo el cuerpo, no solo con el cerebro, sino también con las neuronas situadas fuera de la cabeza y las terminaciones principales del sistema nervioso. Además, como explica Francisco González, los sentimientos y emociones que se vuelcan en una obra creativa (todos, en general, pero estos también), son gestionados por la mente «mediante una acumulación continua de estímulos marcados somáticamente cuyo sistema de adquisición parece hallarse en las cortezas prefontales del cerebro» $(2018,38)$, a la luz de las investigaciones dirigidas por el neurocientífico Antonio Damasio. El propio Damasio explica una cuestión, la de la reelaboración literaria de la memoria, que afecta tanto a este poema de Segovia como a otros que veremos en este artículo: es normal que el escritor seleccione uno o varios episodios puntuales de su pasado para recrearlos, puesto que el «sí mismo autobiográfico»-tercer grado de conciencia, solo al alcance del ser humano, por el cual el ser consciente puede elaborar un relato de sí, entendiendo «el yo como el centro de gravedad narrativa» (Dennett 1991; 2017, 307)- solo precisa una serie de hitos en su memoria para reconstruir su identidad. «Ni siquiera Proust», comenta Damasio, «hubiera necesitado apoyarse en todo su pasado ricamente detallado y desde hacía tanto tiempo desvanecido para construir un momento de su plena autoprousticidad» $(2010,321)$. Aunque el relato, como explica Damasio, no tiene por qué ser lingüístico per se, es obvio que para un poeta hay una confusión inmediata entre la forma de relatarse y el lenguaje, que suele cobrar en estos casos, y desde luego en el poema de Segovia, intensidades casi performativas.

Veamos otra dimensión del motivo hiperfrontal en este poema de Miguel Casado (1993, 22):

\author{
ES EXTRAÑA ESTA SENSACIÓN \\ de reconocerme. Iba andando \\ de una cita a otra, era por la tarde; \\ cuando pasaba ante las tiendas \\ me veía en el cristal, me verían así \\ los transeúntes; por ejemplo, reconozco \\ mis entradas, son inequívocas,
}


la piel de la cabeza bajo el pelo corto, como pelusa; hay, en cambio, de épocas distintas, recientes incluso, fotos con larga melena, hasta los hombros: me desconciertan. Ni mirándolas percibo el paso del tiempo, soy sólo así, como soy ahora; es inverosímil esa historia en que parezco otro, la opacidad de las imágenes que guardan los testigos. Pero hablo de entonces, no sé si por hábito, y asumo aquellos hechos, son míos, de quien soy ahora, y paseo como en una película este cansancio, el desánimo a veces, por aquellas tardes excitadas y turbias en las esquinas de barrios ya destruidos; relato: las calles se retorcían casi sin luz, la representación del amor lo creaba al acumular sus signos. Mi memoria es débil, aunque basta para dotarme de argumento como a todo el mundo; en él cambian las visiones de las cosas y no cambia su nombre, así continúo refiriéndome proyectos - una casa entre árboles en la ciudad idealizada, el discurso del personaje fracasado en el rigor de su éxito, la arena del desierto y los jinetes de caballos menudos- como si se tratara de los proyectos de siempre. «Soy tenaz», me digo, «al final todo resulta», y encuentro cada vez razón a las modificaciones de este catálogo, a los abandonos; todo resulta, llega, al final de los actos inanes, de su suma surge la maravilla... y prefiero ya, mejor que la otra, esta casa comentada sobre un río contado en algún poema, o quizá antes pasé una temporada en el campo.

Si le dedico tiempo, unos minutos con la vista fija en los balcones de enfrente, en las antenas y los ladrillos y el cielo, aquella sensación se hace extraña, reconocerme, el convencimiento de que pervivo a través de los años. Viene, sin embargo, nítida e intensa, de pronto; 
sé de su verdad

como también de su impostura.

Este texto tiene la virtud de alertar contra algunas presunciones; la primera, la consideración de la memoria como registro intocable; la segunda, y no por contradictoria con la primera menos comprensible, la imposibilidad del sujeto de pensarse sin memoria, por falaz o alterada que esta sea; en tercer lugar, el poema aniquila el mito del cerebro técnico, autosustentado en su funcionamiento, según el cual idénticos estímulos fisiológicos habrían de producir iguales resultados (iguales poemas, por ejemplo). Ese mito es combatido por Barthes en sus Mitologías, cuando habla con humor de «El cerebro de Einstein» en su ensayito homónimo, describiendo la lucha de dos hospitales por el cerebro muerto del científico alemán: «El pensamiento es representado como una materia energética, producto mensurable de un aparato complejo (poco menos que eléctrico) que transforma la sustancia cerebral en fuerza» $(2005,93)$. Fuerza susceptible, en consecuencia, de ser transmitida y transformada, sin crearse ni destruirse, solo transformándose. El poema de Casado enfrenta los como si lingüísticos al relato del sí mismo autobiográfico, estableciendo distintas posibilidades o potencialidades, a la vez que se recogen las inestabilidades propiciadas por una memoria infiel, que vale poco como registro, pero sí como suma de plataformas mudables de observación desde las que examinarse examinándose.

Y todavía podríamos citar otros varios ejemplos poéticos más puntuales de metacognitividad hiperfrontal: «Aparecen / desagradables cracks en los muebles / se desestabiliza este coraje que provoca / sensación de estar entre dos mundos. / En uno, el poema que no llega / se detiene para atenderlo» (Concha García 2013, 57); «De la piel al centro del cráneo. El cerebro no duele, dicen. No duele aquello que piensa, duele lo que se piensa» (Chantal Maillard 2015, 82); «¿De dónde vienen tus sueños, sino de esas latas / que alguien abre dentro de tu mente? / Alguien proyecta la estrella: un holograma. / Alguien proyecta la casa. / Alguien proyecta este hombre que escribe / dentro de la casa bajo la estrella: un holograma / que escribe una serie de objetos destruidos» (Juan José Rodinás 2018, 63); «Mis sentidos me dicen cuanto sé de este instante. / [...] Cierro los ojos para ver mejor; aguzo los oídos para apreciar en los sonidos / las dimensiones del espacio» (Juan Manuel Benítez Ariza 2018, 11); o «La actividad mental que se genera en mi cerebro cuando escribo, me hace feliz. Es una sensación momentánea, un momento de vida» (Miriam Reyes «Yo, interior, cuerpo», en Iglesias Serna 2017, 142). Clara Janés incluye en Estructuras disipativas (2017) un poema titulado «Confidencia al conejo de la anunciación», donde pueden leerse estos versos: «Dice que la conciencia / no es sujeto de conocimiento. / ¿Y lo es, acaso, el conocimiento? // Luminoso -aunque me ignora- / cruza mi mirada y me mantiene en vela» $(2017,89)$. Y José María Álvarez, en «De 'Signifying Nothing'», apunta: «haremos / hasta que nuestro pensamiento sea / como un guijarro limpio, pulido por las aguas, hasta que entendamos / que aunque 
miramos, ya no vemos, pero aún miramos, / que aunque pensamos, ya no sabemos, pero aún / pensamos» $(2015,63-64)$. También, para terminar, citaremos este breve poema de Marta Agudo (2004, 35):

Contorno de inquietud:

neurona enferma

que gira en su curso

ferviente hasta la red.

Poema en el que late la conciencia de la fisicidad del pensamiento, la clara percepción de que ningún dualismo puede justificar la inexistencia de una distinción entre «mente» y «cuerpo».

\section{Conclusiones}

El poema es conciencia hecha palabra. Juan Manuel Uría $(2018,12)$

Hemos visto varios ejemplos de poetas viéndose pensar, «y pensar querría decir aquí algo así como: hablar con uno mismo» (Wittgenstein 2017, 67), pues el lenguaje que encarna el pensamiento es también pensable en varios de estos poemas. Con una doble voz, los poetas se dirigen a sí mismos y al lector, convirtiendo la lectura en un pasaje -en un paisaje- compartido. Esto sucede porque el poeta entiende, instintivamente, a la luz de la eximia tradición que le precede en el tiempo, que el poema es el lugar natural en el que un escritor se pregunta por el proceso del pensamiento, por la ontología de la conciencia. Amelia Gamoneda, en este sentido, habla del «permanente experimento de vinculación entre physis y conciencia que es la poesía» $(2016,81)$. Junto al razonar filosófico, el poema parece el espacio propicio de la metarreflexión, del pensamiento sobre el pensamiento - desde una perspectiva estética, en los casos de los diversos poetas estudiados-.

En varios de los autores incluidos en este recuento, además, se advierte un conocimiento real, incluso explicitado mediante citas o referencias, de los descubrimientos y avances neurocientíficos realizados en los últimos decenios, de modo que conceptos como las neuronas espejo o las zonas cerebrales responsables del lenguaje se incorporan sin estrépito como parte del argumentario o del sistema metafórico, algo también indiciario de la metacognitividad hiperfrontal como forma de ahondamiento en las posibilidades expresivas y cognitivas de la escritura poemática.

Para terminar, veamos un último poema de uno de los vates metacognitivos por excelencia, como apuntamos más arriba, Wallace Stevens. En él parece que 
el yo poético ha conseguido dejar atrás la playa gris de la resistencia al acceso, atravesando todo el bloque de arranque del cerebro hasta llegar al final mismo del ser. Con estos versos se abre su estremecedor poema "Of Mere Being», «De la simple existencia» $(2006,236)$ :

The palm at the end of the mind, Beyond the last thought, rises

In the bronze decor,

A gold-feathered bird

Sings in the palm, without human meaning,

Without human feeling, a foreign song.

En traducción de Andrés Ibáñez: «La palmera del final de la mente, / más allá del último pensamiento, se eleva / en el decorado de bronce. / Un pájaro de plumas doradas / canta en la palmera, sin significado humano, / sin humano sentimiento, una canción extranjera» (1999). Quizá nunca sepamos si esa llegada al final del yo es vera, pero desde luego no cabe duda de que está bien trovata.

\section{BiBLIOGRAFÍA}

Abad, Luis Ángel. 2002. Rock contra cultura. Madrid: Biblioteca Nueva.

Abrams, M. H. 1992. El Romanticismo: tradición y evolución. Trad. Tomás Segovia. Madrid: Visor Distribuciones.

Agudo, Marta. 2004. Fragmento. Salamanca: Celya.

Agudo, Marta. 2009. «La cualidad quebradiza del poema. Entrevista a Olvido García Valdés». Letra Internacional 102: 80-85.

Agudo, Marta. 2021. Sacrificio. Madrid: Bartleby Editores.

Aguilar Bautista, Virginia. 2010. Seguir un buzón. Sevilla: Renacimiento.

Aira, César. 2012. Entre los indios. Buenos Aires: Mansalva.

Alcantarilla, María. 2017a. La edad de la ignorancia. Madrid: Visor.

Alcantarilla, María. 2017b. Un acto solitario. Sevilla: La Isla de Siltolá.

Álvarez, José María. 2015. El oro de los tigres. Cartagena: Badulque.

Amorós, Andrés. 1987. Introducción a la literatura. Madrid: Castalia.

Armstrong, Paul B. 2013. How Literature Plays with the Brain: the Neuroscience of Reading and Art. Baltimore: The Johns Hopkins University Press.

Balzac, Honoré de. 1966. La comedia humana. Ed. Augusto Escarpizo; trad. Juan Godo Costa, José M. ${ }^{a}$ Aymamí y Antonio Ribera. Tomo XXVI. Barcelona: Editorial Lorenzana.

Barthes, Roland. 2005. Mitologías. Trad. H. Schmucler. Madrid: Siglo XXI.

Bartra, Roger. 2007. Antropología del cerebro. La conciencia y los sistemas simbólicos. México D. F. - Valencia: Fondo de Cultura Económica - Pre-Textos.

Beecher, Donald. 2016. Adapted Brains and Imaginary Worlds. Cognitive Science and the Literature of the Renaissance. Montreal: McGill-Queen's University Press. 
Benéitez, Rosa. 2019. José-Miguel Ullán. Por una estética de lo inestable. Madrid Frankfurt: Iberoamericana - Vervuert.

Benítez Ariza, José Manuel. 2018. Arabesco. Valencia: Pre-Textos.

Bermúdez, Víctor E. 2017. «Prospecciones cognitivas de la percepción en la poesía de Lorand Gaspar». En Inscriptions littéraires de la science, Épistémocritique, ed. Amelia Gamoneda y Víctor E. Bermúdez, 39-52. Paris: Épistémocritique

Blackmore, Susan. 2010. Conversaciones sobre la conciencia. Trad. Francesc Forn. Barcelona: Paidós.

Bloom, Harold. 2003. «La desintegración de la forma». En Deconstrucción y crítica, Harold Bloom, Jacques Derrida, Geoffrey Hartman, Paul de Man y J. Hillis Miller; trad. Mariano Sánchez Ventura, 11-46. Buenos Aires: Siglo XXI.

Cabrera, Antonio. 2016. Corteza de abedul. Barcelona: Tusquets.

Carreiras, Manuel. 1997. Descubriendo y procesando el lenguaje. Madrid: Trotta.

Casado, Miguel. 1993. Falso movimiento. Madrid: Cátedra.

Castrillón, José María, ed. 2018. Subir al origen. Antología comentada de poesía occidental no hispánica. Gijón: Trea.

Changeux, Jean-Pierre. 2010. Sobre lo verdadero, lo bello y el bien. Un nuevo enfoque neuronal. Trad. Julia Bucci. Buenos Aires: Katz.

Chávez, Rosa, Ariel Graff Guerrero, Juan Carlos García Reyna, Victor Vaugier y Carlos Cruz Fuentes. 2004. «Neurobiología de la creatividad: resultados preliminares de un estudio de activación cerebral». Revista Salud Mental 27 (3): 38-46.

Damasio, Antonio. 2010. Y el cerebro creó al hombre. Trad. Ferrán Meler Orti. Barcelona: Destino.

Dehaene, Stanislas. 2009. Reading in the Brain. The Science and Evolution of a Human Invention. Nueva York: Viking Penguin.

Dehaene, Stanislas. 2018. En busca de la mente. Trad. Luciano Padilla. Buenos Aires: Siglo XXI.

Dennett, Daniel C. 1991. Consciousness Explained. Boston: Little Brown.

Dennett, Daniel C. 2017. De las bacterias a Bach. La evolución de la mente. Trad. Marc Figueras. Barcelona: Ediciones de Pasado y Presente.

Derrida, Jacques. 1978. De la gramatología. Trad. Oscar del Barco y Conrado Ceretti. México D. F.: Siglo XXI Editores.

Dickinson, Emily. 1997. Selected Poetry. Nueva York: Doubleday.

Dickinson, Emily. 2011. Oblicuidad de la luz (95 poemas). Ed. y trad. Rolando Costa Picazo. Valencia: Universitat de València.

Doctorow, Edgar Lawrence. 2014. Andrew's Brain. Londres: Abacus.

Eagleman, David. 2013. Incógnito. Las vidas secretas del cerebro. Trad. Damià Alou. Barcelona: Anagrama.

Eagleman, David. 2017. El cerebro. Trad. Damià Alou. Barcelona: Anagrama.

Eagleton, Terry. 2017. Cultura. Trad. Belén Urrutia. Madrid: Taurus.

Enzensberger, Hans Magnus. 2002. Los elixires de la ciencia. Miradas de soslayo en poesía y prosa. Trad. J. L. Reina Palazón. Barcelona: Anagrama.

Gamoneda, Amelia. 2016. Del animal poema. Olvido García Valdés y la poética de lo vivo. Oviedo: KRK Ediciones.

Gamoneda, Amelia. 2017. «De l'optique au mental. La poétique cognitive de Bernard Noël». En Inscriptions littéraires de la science, Épistémocritique, ed. Amelia Gamoneda y Víctor E. Bermúdez, 23-37. Paris: Épistémocritique.

García, Concha. 2013. El día anterior al momento de quererle. Madrid: Calambur.

García, David Leo. 2011. Dime qué. Barcelona: DVD Ediciones. 
García, David Leo. 2018. Nueve meses sin lenguaje. Barcelona: Ultramarinos.

García, José Daniel. 2008. Coma. Madrid: Hiperión.

García Valdés, Olvido. 2008. Esa polilla que delante de mí revolotea. Poesía reunida (19822008). Barcelona: Galaxia Gutenberg.

Goldberg, Elkhonon. 2009. The New Executive Brain: Frontal Lobes in a Complex World. Nueva York: Oxford University Press.

González Fernndez, Francisco. 2012. Esperando a Gödel. Literatura y matemáticas. Tres Cantos: Nivola.

González Fernández, Francisco. 2018. «Introducción. Autorretrato del matemático como artista». En La invención matemática. Cómo se inventa: el trabajo del inconsciente, Henri Poincaré; ed. y trad. Francisco González Fernández, 9-55. Oviedo: KRK Ediciones.

Hall, Stuart. 1997. «The Work of Representation». En Representation. Cultural Representations and Signifying Practices, ed. Stuart Hall, 1-74. Londres: Sage.

Harris, Lasana T., Victoria K. Lee y Beatrice H. Capestany. 2014. «The Cognitive Neuroscience of Person Perception». En The Cognitive Neurosciences, ed. Michael S. Gazaniga y George R. Mangun, 995-1002. Cambridge: Massachusetts Institute of Technology.

Hofstadter, Douglas R. 2008. Yo soy un extraño bucle. Trad. Luis Enrique de Juan. Barcelona: Tusquets.

Ibáñez, Andrés. 1999. «El poeta del fin de la mente». Revista de Libros 27. http://www. revistadelibros.com/articulos/la-poesia-de-wallace-stevens

Ibáñez, Andrés. 2018a. Construir un alma. Manual de meditación para el siglo XXI. Barcelona: Galaxia Gutenberg.

Ibáñez, Andrés. 2018b. El rostro verdadero. Novela en cuatro cantos. Madrid: Estática Libros.

Iglesias Serna, Amalia, ed. 2017. Sombras di-versas. Diecisiete poetas españolas actuales (1970-1991). Madrid: Vaso Roto.

Janés, Clara. 2017. Estructuras disipativas. Barcelona: Tusquets.

Jiménez, Juan Ramón. 1959. Libros de poesía. Madrid: Aguilar.

Jnaneshvar. 2013. Carta a Changadeva. Trad. Jesús Aguado. Málaga: Árbol de Poe.

Jung, Carl Gustav. 2002. Mysterium coniunctionis. Obra completa, vol. 14. Trad. Jacinto Rivera y Jorge Navarro. Madrid: Trotta.

Kandel, Eric R. 2013. La era del inconsciente. La exploración del inconsciente en el arte, la mente y el cerebro. Trad. Genís Sánchez Barberán e Ignacio Villaro Gumpert. Barcelona: Paidós.

Kuffler, Stephen W. y John G. Nicholls. 1976. From Neuron to Brain. Sunderland, Massachusetts: Sinauer Associates.

Kukkonen, Karin. 2017. A Prehistory of Cognitive Poetics. Neoclassicism and the Novel. Oxford: Oxford University Press.

Luján Atienza, Ángel Luis. 2006. «El estudio de la poesía desde una perspectiva cognitiva: panorama y propuesta». Revista de Literatura, LXVIII, 135: 11-39. https://doi.org/10.3989/revliteratura.2006.v68.i135.1

Maillard, Chantal. 2015. La mujer de pie. Barcelona: Galaxia Gutenberg.

Martínez, Erika. 2017. Chocar con algo. Valencia: Pre-Textos.

Méndez González, Iván. 2017. «Hueco que deja tu mano en la piel». En \#Nodos, ed. Gustavo Ariel Schwartz y Víctor Bermúdez, 324-326. Pamplona: Next Door Publishers.

Méndez Rubio, Antonio. 2016. Abierto por obras. Ensayos sobre poética y crisis. Madrid: Libros de la resistencia.

Mora, Vicente-Luis. 2016. El sujeto boscoso. Tipologías subjetivas de la poesía española contemporánea entre el espejo y la notredad (1980-2015). Madrid - Frankfurt: Iberoamericana - Vervuert. 
Nietzsche, Friedrich. 2012. El nacimiento de la tragedia. Ed. Andrés Sánchez Pascual. Madrid: Alianza Editorial.

Osswald, Andrés Miguel. 2014. «El concepto de pasividad en Edmund Husserl». Areté. Revista de Filosofía XXVI, 1: 33-51.

Paz, Octavio. 1990. Los privilegios de la vista. México D.F.: Centro Cultural Arte Contemporáneo.

Pinker, Steven. 2003. La tabla rasa. Barcelona: Paidós.

Pradel, Stefano. 2018. Vértigo de las cenizas: Estética del fragmento en José Ángel Valente. Valencia: Pre-Textos.

Rendón Uribe, María Alexandra. 2009. «Creatividad y cerebro: bases neurológicas de la creatividad». Aula. Revista de Pedagogía de la Universidad de Salamanca 15: 117-135.

Rodinás, Juan José. 2018. Cuaderno de Yorkshire. Valencia: Pre-Textos.

Roessler, Johannes. 2016. «Thinking, Inner Speech, and Self-Awareness». Review of Philosophy and Psychology 7 (3): 541-557. https://doi.org/10.1007/s13164-015-0267-y

Sánchez, Basilio. 2008. Las estaciones lentas. Madrid: Visor.

Schiller, Federico. 1962. Poesía ingenua y poesía sentimental. Trad. Juan Probst y Raimundo Lida. Buenos Aires: Editorial Nova.

Searle, John R. 1996. El redescubrimiento de la mente. Trad. Luis Valdés. Barcelona: Crítica.

Segovia, Tomás. 2005. Día tras día. Valencia: Pre-Textos.

Sielke, Sabine. 2008. «'The Brain - is wider than the Sky -' or: Re-Cognizing Emily Dickinson».

The Emily Dickinson Journal XVII, 1: 68-85. https://doi.org/10.1353/edj.0.0006

Sierra, Germán. 2020. El artefacto. Trad. Javier Calvo. Madrid: De Conatus.

Solso, Robert. 1996. Cognition and the Visual Arts. Cambridge: Massachusetts Institute of Technology.

Steiner, George. 1972. Extraterritorial. Papers on Literature and the Language Revolution. Londres: Penguin Peregrine Books.

Stevens, Wallace. 1987. Adagia. Trad. Marcelo Cohen. Barcelona: Península.

Stevens, Wallace. 1996. Notas para una ficción suprema. Trad. Javier Marías. Valencia: Pre-Textos.

Stevens, Wallace. 2006. De la simple existencia. Antología poética. Trad. Andrés Sánchez Robayna. Barcelona: Debolsillo.

Taranilla, Raquel. 2020. Noche y océano. Barcelona: Seix Barral.

Turner, Mark. 1991. Reading Minds. The Study of English in the Age of Cognitive Science. Nueva Jersey: Princeton University Press.

Uría, Juan Manuel. 2018. La ciencia de lo inútil. Gijón: Trea.

Valéry, Paul. 1972. El señor Teste. Trad. Salvador Elizondo. México: UNAM.

Wittgenstein, Ludwig. 2017. Investigaciones filosóficas. Ed. Jesús Padilla. Madrid: Trotta.

Zeki, Semir. 2009. Splendors and Miseries of the Brain: Love, Creativity, and the Quest for Human Happiness. Malden: Wiley-Blackwell.

Fecha de recepción: 07 de febrero de 2019.

Fecha de aceptación: 15 de marzo de 2019. 
